\title{
DEZ ANOS DE MERCOSUL: UMA VISÃO BRASILEIRA
}

Paulo Roberto de Ameida

SUMARIO: 1 - O Mercosul como processo historico e como realidade sociologica, 2- Da integracéco Brasil-Argentina ao Merado Comam do Sul, 3- A econonid a servico da politica a constucào do Mercosul, 4. Desenvolvimento politico economico do Mercosul de 1991 a 2000 , 5- Esinulura juridico-institucional do Mercosul, 6- Desenwatwento de am espaco integrado 6 democrático na America do Sul, 7- Retaçes intemacionais do Mercosul, 8- O Mercosul como profeto político: perspectivas, 9- Bibliografía.

SUMMARY: 1- The Mercostil like historic process and the soctologic reality, 2- Of integration Brazi-Aygentina to Commom Market of South, 3- The economy seming the politic: the construction of Mercosul, 4- Poltic and economic development of Mercosul 1991 to 2000, 5 Jardic and instiutional stucture of Mercosul, 6- Development of the integrated and democratic space in South America, 7. Internacional relation of Mercosul, 8. The Mercosul tike politic project: perspective, 9- Bibliography.

UBERSICHT: 1- Der Mercosul we ein historical Prozess und einen sociologio Realtot; 2. Con. de Brazil-Argentina Integration bis der Suden allgemein Merket; 3. Die Wirtschaft dass der Politik aspeckt bedienen; 4. Der Politike und Wirtschaft Entwicklung von 1991 bis 2000, 5. Die legal-institutional Strukyur von Mercosul; 6 . En eingegliedert und demokratish entwidlung in Sulden Amerika; 7. Die Intemationd Aufstellungs von Mercosul; 8. Mercosul wie en political Projekt: Se Aussicht (Prspehtive); 9. Die Bibliographie.

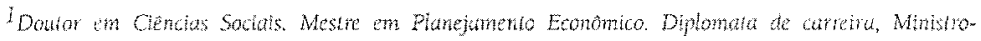
conseticiro nut Embaxida do Brasit em Wushington.
} 
RESUMO: Avaliaça crítica dos primeiros dez anos do MERCOSUL, numa visao brasteira, tratando das seguintes questoes: breve digressäo historica sobre os antecedentes do esquema integracionista, a decisao integracionista adotada pelo Brasil e pela Argentina, o desenvolvimento do MERCOSUL nos anos 1990, suas realizaçoes materiais e frustracoes economicas, scus pressupostos politicos e sua estrutura juridico-institucional, assim como as lacunas remanescentes do processo integracionista, en face dos desafos existentes nos planos regional, hemisferico e global, com destaque para a questäo da Alca.

ABSTRACT: Critical assessment of the first ten years of MERCOSUL, from a Brazilian perspective, dealing with the following questions: brief historical information on the backround process of the integration between Brazil and Argentina, the dection-making process in the context of the 1991 Asuncion treaty, the development of MERCOSUL in the 1990s, its achevements and shortcomings, its political underpinnings and its legal-institutional structure, as well as its unfinished agenda, together with the challenges ahead in the regional, hemispheric and global contexts, in particular the FIAA question.

DER ZUSAMMENFASSUNG: Die erste Kritishe Schatzung Jahre's Morcosul, eine Brazilaninger anzischt aber diese erste Punkte: Kurtz historical Information ob der fruherer Umstand Integration Prozess, die Integrationalist Entswheidung amehme in der Brazil und Argentina, der Mercosul Entwicklung seit 1990, seine materiell Verwinklchunger und die Frustration in die Whrchaft, sein politish Voraussetzung und seine legalinstututional Struktur, so da die Integrationalist Prozess ducke, auf der whanden Herausforderung aus der regional, hemispharik und global Aspehts, sich asuszeichnen als der Alca Problem.

PAIAVRAS-CHAVE: Integraçăo. Brasil. Argentina. Mercosul. Relaçōes internacionais no Mercosul.

KEY-WORDS: Integration. Brazil. Argentina. Mercosul. International relation of Mercosul.

SCHLÜSSELWÖRTER: Integration. Brazil. Argentina. Mercosul Die Intemational Ausfstellungs von Mercosul. 


\section{O MERCOSUL como processo histórico e como realidade sociológica}

\section{O}

MERCOSUL, entendido como processo complexo de construção progressiva de um espaço integrado no Cone Sul, transcende em muito as realizaçóes econômicas, políticas e diplomáticas acumuladas ao longo dos primeiros dez anos de sua existência formal, contados a partir da assinatura do Tratado de Assunção, em 26 de março de 1991. Trata-se de uma realidade sociológica fortemente embasada no contexto histórico e politico do subcontinente sul-americano, extravasando o simples conceito econômico de uniajo aduaneira ou de mercado comum, visto que apresenta caracteristicas imanentes do ponto de vista sócio-estrutural que vão além dos resultados alcançados nos planos comercial, politico-diplomático ou mesmo "societal" dos quatro paises membros. A realidade sociológica e o alcance efetivos do MERCOSUL na geoeconomia e na história politica recente da reglão extrapolam a simples área coberta pelo territótio combinado dos quatro membros originais e dos dois paises associados. Da mesma lorma, seu "tempo histórico" de desenvolvimento ultrapassa a mera cronologia de uma década, devendo-se remontar à segunda metade do século XX para projetar sua inlluência real nas próximas décadas.

0 presente texto pretende oferecer, segundo uma perspectiva brasileira, um balanço crítico dos primeiros dez anos do MERCOSUL em suas diferentes vertentes, e portanto, a avaliaçäo sistêmica aqui proposta está explicitamente formulada a partir dessa visäo nacional do processo integracionista. O texto se propoe a tocar nos seguintes aspectos, que comporão suas seçōes: depois desta introdução ao debate do problema e de uma breve digressão histórica sobre seus antecedentes, serão sucessivamente abordados o problema da "opçăo integracionista" no quadro da histótia política e economica dos países membros na segunda metade dos anos 1980 , com destaque para o protagonismo dos dois sócios principais, o desenvolvimento do MERCOSUL nos anos 1990 , suas realizaçoes materiais e frustraçóes econômicas, seus pressupostos políticos e sua estruturat juridico-institucional, assim como as lacunas remanescentes do processo 
integracionista, em face dos desafios existentes nos planos regional, hemisférico e global.

Qualquer avaliação ponderada de um processo de construção integracionista tão complexo como o MERCOSUL deve partir de premissas realistas e de critérios razoáveis de aferição de resultados e julgat os sucessos alcancados, assim com as insuficiências manifestas do projeto de mercado comum, em sua ótica e méritos próprios, que devem ser os dos objetivos originalmente propostos pelos "pais fundadores" e expressos nos textos constitutivos, nos mandatos ulteriores e nas decisoes derivadas, recusando, portanto, a adoç̃o de uma perspectiva principista que consistiria na crítica à realidade existente a partir de um modelo suposto ideal de integração, geralmente identificado com o padrão europeu. $O$ autor não pretende discutir implicaçōes teóricas ou controvérsias juridicas do MERCOSUL como a falsa oposiça entre o direito comunitário e o direito internacional -, não pertinentes ao objeto em foco e ao espirito deste balanço, que se limita ao desenvolvimento dos processos reais que marcaram seu itinerário nos primeiros dez anos a partir do Tratado de Assunção. Um rápido percurso sobre as origens historicas e os fundamentos economicos do MERCOSUL torna-se entretanto necessário para identificar as diferenças, continuidades e rupturas em relação ao processo imediatamente anterior.

\section{Da integração Brasil-Argentina ao Mercado Comum do Sul}

Os processos de aproximação, de cooperação e de integração entre a Argentina, o Brasil, o Paraguai e o Uruguai, que resultaram no Tratado de Assunção de 1991 e na construção integracionista ulterior, associando ao projeto outros países do Cone Sul latino-americano, possuem antecedentes políticos e estruturais tanto internos quanto externos ao esquema subregional, cujas principais etapas históricas de desenvolvimento poderiam ser sumariadas em tono de algumas datas simbólicas desse longo itinerário que provavelmente ultrapassa meio século de ensaios, logros positivos e frustracóes. 
Com eleito, data do inicio dos anos 1940 , ainda antes da guerra européia ter-se convertido num conflito mundial de proporçöes gigantescas, a tentativa de uma primeira união aduaneira bilateral Brasil-Argentina, aberta à época aos demais paises da sub-região. Tal projeto foi descontinuado não apenas em função dos itinerários políticos diversos seguidos pelos dois paises naquela conjuntura político-militar, como provavelmente também, no plano estrutural, em razão de assimetrias econômicas, da baixa intercomplementaridade industrial e do carâter ainda mais excêntrico de suas respectivas parcerias comerciais externas (Almeida, 1993). O projeto seria renovado no inicio dos anos 50 , por iniciativa peronista, sob a forma de um segundo "Pacto ABC", mas as naturais diferenças politicas e de orientaça diplomática hemisferica entre os govemos dos três países, no contexto da Guerra Fria, sepultaram rapidamente essa tentativa de caráter mais "hegemônico" do que propriamente econômico ou comercial, Dada a referida conjuntura, tanto as primeiras formulaçoes de politicas comercial e industral por parte da CEPAL (dirigida então por Raúl Prebisch) como o exemplo então oferecido pelo núcleo original do mercado comum europeu, incitaram o Brasil e a Argentina a retomarem o projeto integracionista. Vale recordar que, por limitaçōes próprias ao GATT-1947, era impossivel à época constituir uma simples área de preferências tarifárias entre os paises interessados da regiäo ou concluir um pacto comercial bilateral mais avançado entre os dois grandes, razão pela qual foi preciso adotar o formato de uma zona de livre-comércio, consubstanciada na ALALC, criada pelo primeiro Tratado de Montevidéu (1960).

Não é preciso retomar aqui o itinerário de avanços e recuos desse esquema, logo sofrendo as restriçóes políticas dos governos militares ou a competição de projetos mais ambiciosos de integração, como o do Pacto Andino (1969). Na realidade, o Brasil e a Argentina sempre realizaram a maior parte das transações comerciais operadas ao abrigo dos acordos preferenciais da ALALC e dos mecanismos de liquidação de contas previstos no Acordo de Säo Domingo de 1965 (compensaçöes interbancárias à base de créditos recíprocos, contrariamente aos sistemas de pagamentos multilaterais recomendados pelo FMD. O fato é que o Brasil e a Argentina, depois de praticamente duas décadas de objetivos conflitantes - inclusive no que se 
relere ao aproveitamento dos recursos hídricos do Prata - e de uma competição militar tăo irracional politicamente quanto custosa económica e diplomaticamente - pois que envolvendo projetos nucleares sem qualquer correspondência com as realidades estratégicas e de segurança da regiăo e no plano global - decidiram retomar, o projeto de construção progressiva de um mercado comun bilateral, tal como inicialmente proposto nos anos 1950 por pioneiros da integração como Hélio Jaguaribe (Almeida, 1993). A reaproximaça nos anos oitenta entre Brasil e Argentina foi possivel graças ao contexto dos processos de redemocratizaça politica e dos novos esquemas preferenciais existentes ao abrigo do segundo Tratado de Montevidé (de 1980, que crion a ALADI, sucessora da ALALC) e da cláusula de habilitaço do GATT (tal como emanada da Rodada Tóquio de negociações comerciais multilaterais, em 1979).

A lase que se estende do Programa de Integração e de Cooperação Economica, desenhado em 1986 por diplomatas de ambos os países sob a liderança dos presidentes Raul Alfonsin e José Samey, até a Ata de Buenos Aires de juho de 1990, passando pelo Tratado de Integração de 1988 , corresponde a um processo bilateral de aprofundamento do movimento integracionista, que não tinha por motivação excluir outros parceiros subregionais, e cuja vocaçâo primária era inteiramente condizente com o projeto de industrialização competitiva dos dois paises e de fortalecimento de um centro economico próprio no contexto subregional. Foi o caso, por exemplo do Unuguai, que acompanhou cada um dos entendimentos mantidos na segunda metade dos anos 1980 pelos seus dois vizinhos, mas que não desejou associar-se a eles. Até entào, a liberalização recíproca do comércio e a deliniça de politicas setoriais comuns obedecia a uma lógica industrial e de fortalecimento conjunto da base econômica subregional. Os fundamentos empiricos do processo bilateral nessa fase eram lornecidos por um novo modelo de integraça que combinava elementos "dirigistas" da experiencia comunitária européia (a constituiçăo de um mercado comum com o estabelecimento de politicas setoriais comuns, ativamente orientadas para a consolidacáo de estruturas produtivas locais) com a cobertura parcial upica dos esquemas prelerenciais "aladianos" (seleção de setores para a reduça progressiva das barreiras tarifárias e nảo-tanilárias). 
Esse modelo tinha a vantagem de ser claro em seus objetivos de complementaridade industrial, mas acarretava igualmente a desvantagem de requerer a negociação de acordos especificos, sempre parciais, para o estabelecimento do objetivo do mercado comum em dez anos (de 1989 a 1998). Em todo caso, o conceito de MERCOSUL estava lançado, assim como o embrião das futumas instituiçoes intergovernamentais - Conselho de Ministros, Grupo Merado Comum, subgrupos de trabalho - que iriam marcar lodo o processo de integracâo na década que se seguiu e de lato até a atualidade. Em termos de relaçes regionais e internacionais, as politicas extemas do Brasil e da Argentina - e mesmo, de certo modo, suas politicas econônicas internas e extemas - passavam a estar indissociavelmente ligadas e interconectadas, mesmo se, em diversas fases e para questoues tanto tópicas como para elementos mais gerais das filosolias respectivas de cada governo, suas respectivas politicas extemas divergissem por vezes dramaticamente no espirito e na letra da construção integracionista. Os regimes cambiais e as aliancas externas preferenciais são apenas dois dos exemplos mais eloquentes das assimetrias e discordancias que o Brasil e a Argentina continuaram a exibir ao longo dos anos 1990 e mesmo durante momentos de crise do sistema politico internacional e do sistema multilateral de comércio. O elemento novo, contudo, a ser destacado como resulado da integracăo dos anos 1980 seria a de linição de uma relação privilegiada entre os dois países que modificou de forma relevante o cenário estratégico na América do 5 ul.

\section{A economia e o serviço da política: a construçäo do MERCOSUL}

A conjuntura política e econômica, interna e externa ao Cone Sul, mudou significativamente no periodo entre meados de 1985 e final de 1990. As diliceis negociaçóes da Rodada Uruguai para a liberalização do acesso a mercados e para a regulação de setores não cobertos ou insuficientemente cobertos pelas regras do GATT - em serviços, investimentos, propriedade intelectual, agricultura, têxteis - assim como o novo impulso dados aos 
esquemas regionais de liberalizaçăo e de integração introduziram um novo desafio para o esquema concertado entre o Brasil e a Argentina. O debate tinha a ver com o ritmo e a cobertura do processo de integração, juigado por muitos observadores à época como excessivamente lento e cauteloso -. "flexivel e gradual" nos termos dos entendimentos bilaterais. A entrada em vigor do acordo de livre-comércio entre o Canadá e os Estados Unidos em 1989 e a perspectiva de sua extensão a outros paises do hemisfério tal como propugnava a "Iniciativa para as Américas" de George Bush em junho de 1990, a perspectiva de uma "fortaleza Europa" a partir de 1993, prometida pelo Ato único Europeu de 1986, assim como a não conclusão da Rodada Uruguai em dezembro de 1990, em Bruxelas, como previsto no esquema inicial, foram fatores que, tomados conjuntamente, atuaram de maneira decisiva na decisão em lavor da conformação do MERCOSUL.

Sem desconsiderar os fatores extra-regionais acima mencionados, o fator singulat mais importante na tomada de decisão politica em favor do formato quadrilateral do MERCOSUL ocorreu durante os anos iniciais dos governos Carlos Menem e Fernando Collor de Mello, cujo compromisso político foi o de buscar o aprofundamento e a aceleração da integração a dois, reduzindo significativamente (para apenas quatro anos) os prazos e as modalidades previstos no Tratado de 1988. O referido compromisso foi referendado pela Ata de Buenos Aires, em julho de 1990, e suas consequências não se limitaram à mudança de ritmo do processo bilateral, mas aletaram, fundamentalmente, o caráter do processo de integração. Em lugar da abordagem "dirigista" e llexivel" do esquema anterior, a integração assumiu uma natureza livre-cambista e o desmantelamento das barreiras existentes passou a ocorrer de forma automática (Almeida, 1998).

Essa decisão "dramática", tanto em temos políticos como comerciais, determinou uma nova configuração nos equilibrios subregionais, com a convocação de reunióes de consultas entre os principais interessados no processo, que nessa conjuntura envolvia o Chile e o Uruguai, mas não ainda - Paraguai. O país andino do Pacífico logo chegou à conclusão de que não poderia ingressar num projeto de mercado comum cujos pressupostos tarifários iam a contra comente de seu perfil linear de uma tarifa unica e 
exclusiva de $11 \%$, num momento em que Brasil e Argentina ainda exibiam médias tarifárias superiores a $40 \%$, com picos por vezes superiores a $100 \%$. O Chile eximiu-se, portanto, de ingressar no novo esquema subregional, preferindo apostar numa futura negociação comercial com os Estados Unidos (retomada apenas dez anos depois, em dezembro de 2000, e com resultados ainda bastante incertos). O Paraguai, por sua vez, após ter-se provisoriamente reabilitado de uma longa fase ditatorial e caudilhesca, foi incorporado ao esquema negociador com o apoio do Brasil, dado o interesse deste último em disciplinar o comércio ilegal na fronteira entre os dois países.

Como resultado de seis meses de intensas negociaçöes entre os quatro países do Cone Sul, chegou-se à definição de um instrumento plurilateral de integração - conhecido desde então por Tratado de Assunção - cujas linhas básicas, entretanto, já tinham sido dadas pelo tratado de integração bilateral de 1988 e sobretudo pelo esquema livre-cambista bilateral da Ata de Buenos Aires de juitho de 1990. Todos os mecanismos, instrumentos, órgãos e em especial os calendários de desgravação eram essencialmente os mesmos, com algumas exceções tópicas concedidas em termos de prazos maiores (um ano adicional) e de ampliação da lista de produtos sensíveis concedidas aos dois novos sócios menores. Mais importante foram preservadas a reciprocidade política total e absoluta entre os países membros e a igualdade de direitos e obrigações entre eles, inclusive no plano da comada de decisões, a despeito dos diferenciais de peso e importância relativos intra-MERCOSUI ainda mais dramáticos do que aqueles existenies entre os integrantes do outro único esquema historicamente conhecido e exitoso de mercado comum, a Comunidade Européia. Essas assimetrias absolutas existentes no MERCOSUL - com o Brasil representando entre 70 e $80 \%$ de sua massa física, em termos de território, população, produto bruto e comércio exterior - também viriam a existir no NAFTA então em conformaçăo, mas sem o complicador, neste último caso, dos regimes uniformes, das políticas setoriais harmonizadas (ou pelo menos coordenadas) e, sobretudo, da política comercial e da tarifa externa comum que se tornam obrigatórias quando se passa de um simples esquema de livrecomércio para a maior complexidade do mercado comum. 
O MERCOSUL quadrilateral estava, portanto, formalmente criado. com o nome oficial - não de tratado do mercado comum do Sul, como muitas vezes se acredita, mas - de "tratado para a constituição de um mercado comum entre Argentina, Brasil, Paraguai e Unuguai", colocando assim no futuro o que então era um projeto extremamente ambicioso no que se refere a prazos e natureza dos compromissos assumidos (nada menos que a "harmonização de políticas setoriais" $e$ a "coordenação de políticas macroeconômicas", por exemplo). Na letra, como se disse, o Tratado de Assunção nada mais é senão uma reprodução ipsis litteris dos mecanismos estabelecidos na Ata de Buenos Aires, ainda que seu espírito formal tenha sido adaptado ao esquema quadrilateral e que, na fase subsequente de negociaçoes internas e externas, o conteúdo substantivo das politicas econômicas e comerciais adotadas eventualmente por cada um dos quatro membros originais estivesse longe das caracteristicas de ipsis verbis que seria de se esperar de um esquema elaborado de integraça como pretende ser um mercado comum. Essa característica se refletiria no desenvolvimento do MERCOSUL, como se verá.

\section{Desenvolvimento politico e econômico do MERCOSUL de 1991 a 2000}

Os dez anos que se seguiram à clata de assinatura do Tratado de Assunçăo, em março de 1991, foram marcados por diferentes fases de desenvolvimento interno e externo do MERCOSUL, tanto em função do seu calendário próprio - definido de maneira bastante otimista, de estabelecimento progressivo e de consolidação do mercado comum (ainda um objetivo năo alcançado, como se sabe) - como em virtude de processos internos e externos que impactaram de forma negativa essas diferentes etapas, sem que os Estados membros lograssem controlar, a cada vez, o itinerário e o desenrolar das forças economicas e politicas em jogo nas tendéncias de curto prazo do futuro mercado comum. A última década pode ser dividida grosso modo em tres etapas: (a) a fase de transição, prevista no próprio tratado, até o final de 1994; (b) a configuração institucional da união 
aduaneira, iniciada formalmente em primeiro de janeiro de 1995, mas que de lato corresponde a uma "segunda fase de transição", pois que abrindo espaço de tempo adicional para que fossem completados os requisitos de uma zona de livre-comércio completo e de uma união aduaneira acabada; (c) finalmente, uma conjuntura de crise política e econômica aberta com a desvalorização do real em janeiro de 1999 e a ameaça subsequente de dolarizaçăo na Argentina. Os contenciosos comerciais e os reclamos protecionistas decorrentes foram em grande medida contornados por um. programa de "relançamento" do MERCOSUL no ano de 2000, a despeito das pressoes dos Estados Unidos e de outros paises (em particular o Chile, que hesita entre a adesão plena ao MERCOSUL e um acordo de livre comércio com os EUA) em favor da antecipaça dos prazos negociadores para a formaça da área de livre comércio hemisférica (ALCA).

Os objetivos fixados no Artigo $1^{\circ}$ do Tratado de Assunção para a fase de transição eram muito claros, a saber: a constituição, até 31 de dezembro de 1994, de um mercado comum, caracterizado pela "livre circulação de bens, serviços e fatores produtivos", pelo "estabelecimento de uma tarifa externa comum" e pela "coordenação das políticas macroeconômicas", assim como o "compromisso dos Estados Partes de hamonizar suas legislaçoes, nas âreas pertinentes". No que se referc, por exemplo, à livre circulaçăo de bens, serviços e latores produtivos entre os paises membros, tal deveria ser atingida por meio, entre outros, da eliminação de direitos allandegários e de restriçoes não-tarifárias à circulação de bens e serviços, ou seja, alcançandose uma zona de livre-comércio. No prazo acordado, as metas foram atingidas apenas parcialmente, essencialmente no que se refere à livre circulaçăo de bens - embora vários produtos permanecessem nas listas de exceçoes, com restriçoes de diversas ordens - mas não no tocante a serviços ou a uma indefinida categoria de "latores produtivos", que poderia ser considerada como o equivalente da circulação de trabalhadores (ou pelo menos de trabalho especializado).

Desse ponto de vista, e mesmo considerando-se uma "segunda fase de mansiçăo" no periodo posterior a 1995 (quando foi estabelecido um programa para o acabamento dos objetivos do Tratado de Assunção conhecido como "MERCOSUL 2000"), O MERCOSUL permanece uma zona 
de livre-comércio incompleta, embora a livre circulação de bens contemple a quase totalidade da pauta aduaneira, pelo menos em número de itens. Entretanto, parte expressiva do comércio intrarregional, senão em volume pelo menos em valor, é composto por produtos do setor automobilístico (automóveis e peças), que permaneceu à margem da zona de livre comércio durante os primeiros dez anos do MERCOSUL. Foi apenas em dezembro de 2000 que, finalmente, se logrou estabelecer um marco comum, quadripartite para o comércio administrado para esse setor, muito embora algumas dúvidas subsistam quanto à capacidade argentina (e dos outros dois sócios menores) de cumprir o acordado. Um acordo-marco para a livre circulaça de servicos - Protocolo de Montevidéu, adotando basicamente o modelo do GATS - foi adotado em dezembro de 1997, prevendo a liberalização progressiva da oferta de serviços inter-regionais num prazo de dez anos, mas sua implementaça depende da negociaça de acordos setoriais especílicos e de compromissos explicitos de abertura, que se encontram atualmente na Segunda Rodada de Negociaçoes.

No que tange a Tarifa Extema Comum, esta foi efetivamente definida nos prazos lixados (isto é, antes de 31.12.94), o que teoricamente converteria o MERCOSUL em uma uniào aduaneira a partir de 1995, mas a implementaçăo da TEC sofreu igualmente novos atrasos temporais e a imposição adicional de regimes temporários de exceção (listas de exceções nacionais, definidas por cada um dos membros, e portanto, diferenciadas e näo aplicadas de forma quadripartite). Outras exceçóes dizem respeito às Listas de Convergencia, acordadas na Reunião Ministerial de Ouro Preto, em dezembro de 1994, para Bens de Capital (com vigência até 01/01/2001 - em lase de renegociação) e para Produtos do Setor de Informática e Telecomunicaçöes (com vigência até 01/01/2006). A TEC se apresenta com uma estrutura racional em termos económicos, comportando em seu regime nomal um leque de dispersão relativamente reduzido (de 0 a 20\%), que esposou caracteristicas da própria tarifa aduaneira brasileira compreensivelmente o país de maior relevancia para o comércio intra e extra-regional. Sob o impacto da crise financeira asiática e em vista os problemas decorrentes do choque de competitividade extemo tanto sobre o Brasil quanto a Argentina, a TEC foi objeto de revisăo em dezembro de 1997 , 
procedendo-se, por meio de acordo quadripartite, a um aumento linear de 3 pontos nas alíquotas efetivas, o que representou um aumento de $25 \%$ na tarifa média de $14 \%$ aplicada geralmente pelos paises membros. Durante a última reuniào do Conselho do Mercado Comum (Florianópolis, $14 \mathrm{e}$ 15/12/2000), os Estados Partes alegaram necessidades fiscais para não procederem à redução integral do aumento transitório da TEC. Nessa ocasião, foi acordada a redução dos níveis tarifários adicionais para 2,5 pontos percentuais, com o compromisso de estabelecer novas reduçōes de acordo com cronograma a ser definido até 30 de junho de 2001. A TEC deveria ser complementada por uma política comercial conjunta dos paises membros em relação a terceiros países, mas diversos elementos dessa politica permaneceram carentes de uma definição, como no caso dos incentivos fiscais. Durante a fase de transição, houve consenso de que se deveriam identificar os casos de política industrial ou fiscal suscetíveis de representar subsidios ou vantagens indevidas para qualquer dos membros, em vista de sua harmonizaçäo ulterior, com vistas a evitar distorçōes comerciais na região. A despeito de esforços conduzidos na fase subsequente, năo houve contudo acordo nesse sentido, o que aliás gerou polêmicas internas relativas a regimes especiais concedidos ao setor automobilístico no Brasil e na Argentina. O Brasil considera que o desmantelamento de sua política de incentivos fiscais e crediticios, como por exemplo os programas promovidos pelo BNDES, vincula-se estreitamente ao correspondente desmantelamento da aplicaça unilateral e abusiva de direitos antidumping e medidas compensatórias no comércio intrazona. A consolidação de uma união aduaneita perde sentido se não forem criados mecanismos e disciplinas comuns nessas duas areas.

No mesmo sentido, o tema da coordenação das paridades cambiais, importante em vista de suas repercussões imediatas nas correntes de comério e nos fluxos de capitais, foi objeto de estudos aprofundados, a partir de uma análise dos regimes cambiais nacionais existentes e do papel, na delinição das paridades recíprocas, do intercâmbio intra e extrazona. Năo se logrou, contudo, uma definição tendente à adoção de um sistema de bandas convergentes ou mesmo um sistema monetário baseado em paridades fixas, tendo em vista os grandes descompassos observados nos 
processos de ajuste e de estabilização macroeconômica, praticamente desde o início do MERCOSUL. A Argentina adotou, como se sabe, a partir de maio de 1991 (Plano Cavallo), uma lei de conversibilidade, sustentada numa paridade absoluta entre o peso e o dólar, enquanto o Brasil tardava até 1994 para iniciar seu processo de estabilização (Plano Real), parcialmente sustentado numa âncora cambial. A despeito da vontade política dos governos dos quatro países membros, fatores de política econômica interna na Argentina e no Brasil (recessão, desemprego, sistemas de câmbio diferentes, processos eleitorais), acoplados às consequências das crises financeiras internacionais de fins de 1994 no México, de 1997 na ásia e de 1998 na Rússia e no próprio Brasil em seguida, causaram sérias dificuldades para a continuada evolução positiva do processo negociador regional.

A desvalorização do real, em janeiro de 1999, e a introdução subsequente de um regime de flutuação cambial deflagraram uma grave crise político-comercial e de credibilidade externa. Na esteira da crise da desvalorização, foi criado, em junho de 1999, o Grupo de Trabalho sobre Coordenação de Políticas Macroeconômicas, com vistas a retomar os entendimentos sobre o tema e propor ações tendentes ao aumento da percepção de creclibilidacle do bloco frente aos investidores internacionais. $O$ exercício quadripartite de coordenação macroeconômica sem clúvida agrega projeção internacional aos programas de estabilidade monetária dos países da região, a despeito das críticas de que foram reduzidos seus resultados concretos e de que os ganhos em termos de credibilidade externa do Brasil se deveram muito mais aos indicadores macroeconômicos alcançados individualmente pelo País do que a qualquer iniciativa ou outro esforço que se possa reputar ao Grupo de Trabalho sobre Coordenação de Políticas Macroeconômicas. É acertado notar, no entanto, que a publicação em outubro de 2000 de indicadores macroeconômicos sobre aspectos fiscais e a antecipação dos prazos previstos para a definição de metas macroeconômicas não foram suficientes, por exemplo, para evitar a atual crise de credibilidade da Argentina nos mercados externos.

A desvalorização do Real foi igualmente impactante em termos políticos e comerciais, dada a imediata reação do setor privado argentino, 
logo encampada pelo Governo de Buenos Aires às vésperas da eleição. receio, que se comprovou infundado, de inundaça de produtos brasileiros nos mercados vizinhos ou de luga de capital para o Brasil reacendeu demandas protecionistas por parte de setores de menor competitividade naquele pais. Foi possivel perceber-se a magnitude do problema, de toda forma, pela queda inédita no volume do intercâmbio intra-MERCOSUL, com a reduçäo do saldo comercial até entäo acumulado pela Argentina contra o Brasil. No ano seguinte, porém, os fluxos de comércio já tinham retomado os valores anteriores à crise financeira, mas subsistiam os problemas de competitividade argentina vinculados em parte a seu regime cambial rígido.

De forma geral, deve-se reconhecer que o MERCOSUL atuou, em seus primeiros dez anos, como uma espécie de mecanismo anti-ciclico no plano das conjunturas econômicas, servindo o Brasil, aliás, como provedor de saldos comerciais para seus parceiros. O bloco constituiu-se em fator eminentemente positivo para a consolidação de políticas orientadas para a estabilizaçăo macroeconomica, para a busca de competitividade interna e externa e para a introdução de medidas de ajuste fiscal e de regimes regulatórios responsáveis e avançados na região. Os avanços, quer no plano da liberalizaçăo do acesso aos mercados recíprocos, quer no terreno da coordenação e harmonização de políticas têm sido mais lentos do que o desejado por seus planejadores originais ou pretendido por alguns entusiastas da integração, mas a cautela na implementação das medidas previstas e necessárias representa, talvez, uma garantia contra retrocessos eventuais.

As crises ocasionais enfrentadas pelos paises membros - que loram confundidas por vezes com crises do próprio MERCOSUL, seja em matérias de imprensa, seja em comentários de observadores menos avisados - deram oportunidade a que alguns desses observadores sugerissem a passagem a instituiçôes supranacionais, quando não à criação de uma moeda única do bloco, como forma de contornar protecionismos setoriais ou de se precaver contra crises financeiras importadas. O falso conflito entre moeda comum do MERCOSUL ou dolarizaça unilateral chegou mesmo a ser agitado no final do mandato do Presidente Menem, merecendo, como seria de se esperar, 
cauteloso tratamento por parte das autoridades económicas no Brasil e na Argentina. A despeito das críticas quanto à morosidade e pouca eficácia do exercicio de coordenaçäo macroeconomica, foram dados em dezembro de 2000 os primeiros passos na direção de um espaço monetário integrado no MERCOSUL, com o anúncio de metas e mecanismos de convergência macroeconômica referentes à: i) variaça da dívida fiscal liquida do setor público consolidado; ii) divida liquida do setor público consolidado (deduzidas as reservas internacionais) sobre o PIB nominal; iii) inflação, com base nas estatisticas hamonizadas elaboradas pelo Grupo de Monitoramento Economico, recentemente criado.

\section{Estrutura juridico-institucional do MERCOSUL}

No âmbito institucional, o Protocolo de Ouro Preto, adotado em dezembro de 1994 para atender ao estipulado no Artigo 18 do Tratado de Assunção, confirmou a escolha básica de 1991 por uma estrutura orgânica de tipo intergovernamental, descartando-se, portanto, o chamado "salto supranacional" desejado por alguns teóricos. Esse Protocolo estabeleceu a seguinte estrutura institucional "definitiva":

a) Conselho do Mercado Comum (CMC): órgão supremo do processo de integração, composto pelos ministros de Relaçoes Exteriores e de Economia; adota decisões;

b) Grupo Mercado Comum (GMC): orgão executivo cuja função é a de assistir o Conselho nas decisóes de natureza executiva; adota resoluções;

c) Comissão de Comércio do MERCOSUL (CCM): assiste o GMC na aplicação dos principais instrumentos de política comercial comum;

d) Comissão Parlamentar Conjunta (CPC): canal de representaça dos Parlamentos dos quatro países, encaminhando suas propostas ao CMC;

e) Foro Consultivo Econômico-Social (FCES): permite aos 
dilerentes setores da sociedade (sindicatos, consumidores, sociedade civil em gerai) encaminhar seus pleitos e proposiçöes aos órgãos de decisão, no seu caso ao GMC;

1) Secretaria Administrativa do MERCOSUL (SAM): com sede em Montevidéu e vinculada ao GMC, faz o registro das decisóes tomadas pelos órgãos permanentes e facilita o processo de solução de controvérsias na fase arbitral.

Desde a assinatura do Tratado de Ouro Preto, a estrutura institucional tem soliido pequenas modificacões, caracterizadas principalmente pela criação de novos foros. A última reestruturaçăo institucional do MERCOSUL foi aprovada pela Decisão CMC No. 59/00, durante a XIX Reunião Ordinária do CMC (Florianópolis, 14 e 15/12/2000). Cabe recordar apenas que o relançamento criou foros informais e paralelos à estrutura institucional, como forma de dinamizar e elevar a importância política de certos temas. Alguns desses Coros informais foram finalmente incorporados à estrutura ao final da Cupula de Florianópolis. Sem alterar a estrutura dorsal do MERCOSUL, a Decisão $59 / 00$ consagra a seguinte estrutura institucional do MERCOSUL:

\section{1- Grupo Mercado Comum}

A- Subgrupos de Trabaho: passam a ser em número de quatorze, a saber: SGT-1 "Comunicaçoes"; SGT-2 "Aspectos Institucionais" (o antigo SGT-2 "Mineraçăo" fundiu-se com o SGT-9; e foi incorporado o antigo Grupo Ad Hoc de Aspectos Institucionais); SGT-3 "Regulamentos Técnicose Avaliação de Conformidade"; SGT-4 "Assuntos Financeiros"; SGT-5 "Transportes"; SGT-6 "Meio Ambiente"; SGT -7 "Indústria"; SGT-8 "Agricultura"; SGT-9 "Energia e Mineração"; SGT-10 "Assuntos Laborais, Emprego e Seguridade Social"; SGT-11 "Saúde"; SGT-12 "Investimentos" (incorporou a antiga Comissâo de Investimentos do SGT-4); SGT-13 "Comércio Eletrônico" (incorporou o antigo Grupo Ad Hoc sobre Comércio Eletrônico); SGT-14 "Acompanhamento da Conjuntura Economica e Comercial" (incorporou o antigo Grupo Ad Hoc de Acompanhamento da Conjuntura Economica e Comercial). 
B- Reunioes Especializadas: passam a ser em número de oito, a saber: "Autoridades de Aplicação em Matéria de Drogas, Prevenção de seu uso indevido e Recuperação de Drogadependentes"; "Mulher"; "Ciência e Tecnologia"; "Comunicação Social"; "Turismo"; "Promoça Conercial"; "Municipios/Intendências do MERCOSUL"; "Infra-estrutura da Integração".

C- Grupos Ad Hoc: passam a ser em numero de quatro, a saber: "Concessoes"; "Setor Açucareiro"; "Compras Governamentais", "Relacionamento Externo".

D- Comitè de Cooperação Técnica

E- Comitê de Diretores de Aduana

F- Comitê de Sanidade Animal e Vegetal

G- Grupo de Serviços

\section{2- Comissão de Comércio do MERCOSUL}

Os Comites Técnicos: passam a ser em número de sete, a saber: CT-1 "Tarifas, Nomenclatura e Classificação de Mercadorias"; CT-2 "Assuntos Aduaneiros"; CT-3 "Normas e Disciplinas Comerciais"; CI-4 "Políticas Públicas que Distorcem a Competitividade"; CT-5 "Defesa da Concorrencia"; CDCS "Comitê de Defesa Comercial e Salvaguardas; CT-7 "Defesa do Consumidor". Foram eliminados o CTr8 "Barreiras Não-Tarifárias" (tema em tratamento no âmbito do Grupo informal de Acesso a Mercados), CI-9 "Automotivo" (tema definitivamente incorporado ao MERCOSUL pela Decisão 70/00) e CT-10 "Textil".

Muito embora as finalidades do MERCOSUL tenham sido muitas vezes definidas como tendencialmente correspondentes aos objetivos perseguidos pelo processo de integração européia, não se julgou necessârio em Ouro Preto que o sistema institucional seguisse os mesmos padróes que aqueles implementados no âmbito do Tratado de Roma. Buscou-se, ao contrário, garantir um modelo que correspondesse às realidades intrinsecas - com todas as limitaçes de fato existentes - do esquema subregional, preservando os espaços de soberania nacional alocados aos Estados membros. Os responsáveis políticos pelo processo de integração estavam 
conscientes de que qualquer "salto supranacional" nessa fase preliminar de implantação da uniào aduaneira, poderia comprometer os objetivos nacionais de estabilização macroeconômica ou alterar o delicado equilibrio entre competências nacionais e atribuiçoes decisórias coletivas.

Do ponto de vista da tomada de decisoes nos órgãos politicos do MERCOSUL - Conselho e Grupo Mercado Comum - o sistema adotado é o consenso entre os Estados Partes e na presença de todos os seus membros. Esse processo tem suas vantagens, mas também apresenta inconvenientes. Ao mesmo tempo em que ele leva os quatro Estados a se colocarem de acordo para adotar uma decisão válida, ou seja, obriga a uma negociaca exaustiva de cada ponto relevante da agenda conum, ele introduz uma certa rigidez estrutural no encaminhamento dos problemas, ao colocar os quatro países em pé de igualdade, independentemente de seu peso econômico relativo ou da magnitude de seus interesses na construção da nova área de integraç̃o.

No que tange a resolução de diferendos entre os membros, o Protocolo de Brasilia (1991) adotado para o periodo de transiça instituiu um sistema de solução de controvérsias que foi confirmado, em suas grandes linhas, pela conferência de Ouro Preto. O mecanismo prevê quatro instâncias resolutivas, com procedimentos adequados a cada uma delas: além de negociaçóes diretas entre as partes envolvidas e da intervenção do Grupo Mercado Comum, já previstas no próprio Tratado de Assunção, adotou-se o recurso a um sistema arbitral (por meio de um Tribunal ad hoc) e previu-se igualmente um procedimento para as reclamaçōes formuladas por particulares, não necessariamente mais expedito. O Protocolo de Ouro Preto agregou mais uma instancia resolutiva: após o término insatisfatório de negociacóes diretas, é possível levar o litígio à consideração da Comissão de Comércio, antes de submete-lo à apreciaçăo direta do GMC. Essencialmente, os mecanismos previstos configuram dois métodos complementares de soluçăo de controvérsia: a via diplomática tradicional de negociação e o recurso à instância jurisdicional de caráter arbitral. Aperfeiçoamentos nesse sistema, tendentes a acelerar a transição entre os procedimentos, deveriam ter sido introduzidos no final de 2000 , mas não houve consenso entre os países 
membros sobre os pontos identilicados: eles previam, basicamente, a eliminação da fase do GMC, o reforço do laudo arbitral, critérios para a conformaçäo de listas de especialistas e árbitros (criação de lista específica de árbitros-presidentes, com dois por país, o que poderia trazer maior harmonia entre os laudos) e alternativas para uma interpretaçäo uniforme da normativa MERCOSUL (comportando algumas estipulaçoes para a fase pós-lando, entre elas sua implementaçăo e eventual retaliaçoes, a exemplo do que já existe na OMC).

\section{Desenvolvimento de um espaço integrado e democrático na América do Sul}

A evolução da interdependéncia econômica no Cone sul e a conformação de um espaço econômico integrado e democrático na América do Sul Coram dois processos não inteiramente controlados pelos estadistas, diplomatas ou pelos demais responsáveis pela administraça da implementação do Tratado de Assunção nestes dez primeiros anos do MERCOSUL. Ainda assim, algumas das açoes resultaram de iniciativas dos proprios dirigentes do processo integracionista no Cone Sul, enquanto outras emergiam como reação ou efeito indireto de eventos ou processos politicos e econômicos oconidos na regiăo nesse periodo, aos quais os governos dos países membros procuraram enquadrar na agenda de trabalho do projeto integracionista. Algumas dessas novas iniciativas devem ser sublinhadas, uma vez que elas confirmam a vocação do MERCOSUL em ultrapassar seus meros efeitos comerciais ou derivaçōes econômicas no sentido de fimar-se como polo de desenvolvimento desse espaço integrado e democrático na América do Sul, objetivo implicito na letra e no espírito do tratado. As duas realizacóes significativas a esse respeito referem-se à chamada "cláusula democrática" do MERCOSUL, impulsionada involuntariamente pelas desventuras políticas do Paraguai, e à valorização do conceito de América do Sul no planejamento político-diplomático do futuro do MERCOSUL, elemento tributável inteiramente à diplomacia brasileira. 
A rigor, a valorização do regime democrático como princípio organizativo básico da integração precede o próprio MERCOSUL, uma vez que, desde a Declaração de Iguaçu, em novembro de 1985, Brasil e Argentina nunca cessaram de reiterar a adesão aos valores democräticos como uma das vigas mestras da construção dos projetos de cooperação e de integração, tanto bilateralmente como na regiāo, de modo mais amplo. A invocação tinha sua razão de ser, em virtude da recente transição política em ambos os países e da existência, sobretudo no vizinho platino, de bolsoes antidemocráticos entre os militares e de grupos dispostos a tutelar, quando não a contestar, as democracias renascentes e sua valorização do jogo políticopartidário. Mas essa adesão à democracia e a seus procedimentos somente adquire siatus de requerimento indispensável à participação no processo integracionista - só se torna um binding principle, como diriam os anglosaxões - quando por duas vezes ocorre a ameaça de ruptura do regime democrático no Paraguai. Em ambas as ocasiỏes, os paises do MERCOSUL: liderados por Brasil e Argentina, emitiram declarações e produziram instrumentos apropriados no âmbito do MERCOSUL com o objetivo explícito de salvaguardar năo apenas a aparència, mas se possivel a essência do sistema democrático no Paraguai.

Em 1996, por exemplo, foi assinada a Declaração Presidencial sobre o "Compromisso Democrático no MERCOSUL", pela qual os quatro paises assumiram o compromisso de consultarem-se e de aplicarem medidas punitivas, dentro do espaco normativo do bloco, em caso de ruptura ou ameaça de ruptura da ordem democrática em algum Estado nembro. Tratava-se, numa primeira abordagem, de uma fómula branda, mas ela tinha sido de todo modo implementada previamente, na prátca, pela aça decisiva da diplomacia brasileira - secundada pelos Estados Unidos, Argentina, União Européia e outros países, inclusive com a ameaça de boicotes e sançóes punitivas - quando da primeira tentativa de golpe militar por parte do General Lino Oviedo. De fato, um golpe de estado bem sucedido no Paraguai violaria antes o espírito do que a letra do Tratado de Assunçăo e apesar de que os presidentes da Argentina e do Brasil tivessem advertido que um tal evento suscitaria a expulsão do Paraguai do 
MERCOSUL, não havia, estritamente, base legal para fazêtlo (Dahène, 2000, p.154)

Na segunda vez, se tratou do assassinato do vice-presidente, crime no qual teria estado implicado o mesmo General Oviedo e que desatou nova crise politica cujas consequências foram em parte sanadas por igual açäo dissuasoria da cliplomacia brasileira. Desta vez, a reação política foi bem mais enfática, e se traduziu na adoção, no plano dos instrumentos constitutivos do MERCOSUL, do Protocolo de Ushuaia, relativo ao compromisso democrático no MERCOSUL, na Bolívia e no Chile (24/7/1998), que passou a fazer parte integrante do sistema político institucional do bloco, num sentido de condiçăo sine qua, uma vez que comportando como sançăo a exclusão pura e simples do membro no qual ocorresse a "ruptura da ordem democrática" (na verdade, o artigo 5 do protocolo menciona a "suspensão dos direitos e obrigaçōes emergentes" dos processos de integração entre os Estados Partes). Em que pese ao caráter meritório da "cláusula democrática" no MERCOSUL, é mais provável que os elementos dissuasórios mais efetivos em vigor no caso do Paraguai tenham mais a ver com a tradicional política de poder do que com qualquer um de seus instrumentos declaratónios.

No que se refere à valorização do conceito de América do Sul, ele não e propriamente uma realização do MERCOSUL, muito embora a disposição dos membros do bloco - e a própria letra do Tratado de Assunção - seja condizente com uma expansão a novos membros da região (de fato, a abertura encontrada no TA se dirigia implicitamente ao Chile, o único membro da ALADI que não aderia, no momento da assinatura do tratado, a nenhum outro esquema subregional de integraça). A estratégia de uma ampliaça continental sempre pertenceu ao Brasil e ela conheceu vários desenvolvimentos, desde o início da década até os recentes progressos da AlCA. Para registro histótico, lembre-se que esse projeto tinha sido apresentado, na gestão do chanceler Fernando Henrique Cardoso no goveno Itamar Franco, como "Iniciativa Amazonica", depois ampliado em escala continental (pelo chanceler Celso Amorim), sob o formato de uma area de Livre-Comércio Sul-Americana (ALCSA). 
Esse espaço de liberalização não recebeu, contudo, no primeiro govemo Fernando Henrique Cardoso, a continuidade esperada pelos seus proponentes originais e a proposta parecia colocada numa espécie de limbo político pelos negociadores da integração. Nas duas modalidades mencionadas, se previa a negociação de acordos de liberalização comercial entre os paises do MERCOSUL e os demais países do continente (vale dizer os andinos). Tal como apresentado pelo Brasil, o projeto da ALCSA năo despertou entusiasmo nos demais parceiros do MERCOSUL, na medida em que reduzia o impacto do acesso preferencial ao mercado brasileiro por parte desses paises e introduzia um dificil processo de negociaçoes "triangulares" que linha de levar em conta não apenas o chamado "patrimônio histórico" da ALADI, mas ainda acordos de alcance parcial que os países do MERCOSUL $e$ seus associados pudessem manter com outros paises latinoamericanos membros de outros esquemas integracionistas (como passou a ser o caso do México a partir da criação da NAFTA). O tema voltou entretanto a freqüentar a agenda da diplomacia brasileira - e por extensäo a do MERCOSUL - à medida em que a ALCA fazia progressos em direção do cumprimento do programa estabelecido em Miami, em dezembro de 1994, mesmo se a designação ALCSA jả não mais comparecia nos textos e discursos dos dirigentes brasileiros. No intervalo, em 1996, tratou-se de reforcar o bloco do Cone Sul mediante a associação, em esquemas paralelos de livre comércio, do Chile e da Bolfvia, esta úlima membro original do Grupo Andino mas de fato ausente do esquema de união aduaneira implementado parcialmente pela Comunidade Andina.

A conclusão, em 1998, de um acordo-quadro de liberalização do comercio entre os paises do MERCOSUL e a Comunidade Andina veio recolocar num novo patamar os esforços de consolidação de uma zona de livre-comércio na América do Sul, mas de fato muito pouco progresso prático tenha sido feito desde entăo. Mudanças e crises políticas em alguns dos integrantes da CAN (Bolivia, Colombia, Peru, Venezuela e Equador), assim como a virtual paralização da capacidade negociadora externa de outro (Colômbia) ou mesmo a "crise economica" do MERCOSUL em 1999 foram latores que contriburam para dificultar a continuidade das negociaçóes. 
Entretanto, a realização de uma primeira reunião de chefes de Estado da América do Sul em Brasilia, em agosto-setembro de 2000, a convite do presidente Fernando Henrique Cardoso, relançou a iniciativa do espaço económico sul-americano, fixando-se o prazo de dois anos para a conclusão das negociações. A "ALCSA" (conceito não utilizado nos entendimentos com a CAN) representa, para o Brasil, uma opção de médio escopo em face da ALCA, servindo para reforçar o esquema liberalizador no âmbito geográfico da América do Sul como reforço indispensável na barganha política (e no concurso de competitividade) "contra" o esquema hemisférico. O pleno desenvolvimento da ALCSA representaria, para o Brasil, uma estratégía de grande importancia na conformaçăo de um projeto económico próprio para a regiâo, independentemente da vontade política do principal parceiro hemisferico.

Deve-se ressaltar que se trata sempre de constituir áreas restritas de livre comércio, ou seja, parciais tanto na profundidade dos compromissos como no àmbito geográfico, uma vez que parece difícil a integraça de mais um novo membro sul-americano na união aduaneira oficial do MERCOSUL. Assim, a despeito da "importante decisäo" anunciada no contexto do relançamento do MERCOSUL, no ano de 2000 , no sentido da "integração plena" do Chile e da Bolívia ao bloco, tinha-se plena consciência das dificuldades práticas e legais existentes, entre elas a da diferença crucial nas estruturas tarifarias (perfil e valor nominal das alíquotas, mais reduzidas nos dois paises andinos). De resto, o Chile, consoante sua vocaçäo declarada desde o anúncio da "Iniciativa para as Américas", em 1990, buscava prioritariamente um acordo na América do Norte, seja como adesão ao NAFTA, seja como acordo bilateral com os Estados Unidos, possibilidade que foi negada ao país andino ao ter o Congresso americano recusado um mandato negociador nesse sentido ao Executivo em 1996. Não obstante, o Chile já tinha um acordo de liberalização com o México - concluído desde 1991, no âmbito da ALADI - e assinou outro com o Canadá em 1998, contendo muitos dos dispositivos típicos do NAFTA. Curiosamente, pouco tempo antes da reunião de cúpula do MERCOSUL em Florianópolis, em dezembro de 2000 , que deveria "anunciar" a "adesão plena" do Chile ao MERCOSUL, foi divulgada a notícia do início das negociações formais do 
país andino com os Estados Unidos visando à conclusão de um acordo de livre comércio.

\section{Relaçoes internacionais do MERCOSUL}

Antes mesmo da entrada em vigor oficial do MERCOSUL, os quatro membros já negociavam acordos com parceiros externos, como foi o caso do chamado "Rose Garden Agreement" com os Estados Unidos (em junho de 1991), que constituiu uma comissão de comércio e investimentos (meramente para o diálogo, ressalte-se) tal como proposta na "Iniciativa para as Américas". Em maio de 1992, foi a vez da Comissăo Européia, com a qual foi assinado acordo de cooperação técnica, também no formato " $4+1$ ", destinado a subsidiar o MERCOSUL, "em transição para um mercado comum", com informações sobre os requisitos iniciais de um processo progressivo de construção desse tipo de mencado.

O Protocolo de Ouro Preto atribuiu ao MERCOSUL personalidade juridica de direito intemacional, o que consolidou a prática até então observada de negociar de forma quadripartite com terceiros paises ou com grupos de páses, como no caso da Uniào Européia ou no âmbito da projetada ALCA, assim como em organismos intemacionais. Enquadrou-se também nessa perspectiva a definição dos critérios de base para a negociação de acordos de livre-comércio com terceiros países, processo iniciado com o Chile e a Bolivia e estendido progressivamente a outros países ou grupos de paises (como a CAN, o México e a áfrica do Sul, que entraram na agenda negociadora no final da década). Ele também representou um reforço considerável no poder de barganha dos quatro paises em escala mundial, como testemunha o diálogo de alto nivel mantido com a União Européia desde as fases iniciais do MERCOSUL e consubstanciado no Acordo de Cooperaçăo interregional MERCOSUL-UE, firmado em dezembro de 1995. Esse acordo desdobrou-se em negociaçóes concretas para a liberalização comercial a partir de 2000 , as quais deverão levar em conta a "sensibilidade de certos produtos [referência indireta à Política Agricola da UE] e as regras da OMC". 
Um dos principais desafios colocados no futuro do MERCOSUL é representado pelo chamado processo de Miami, que, iniciado em 1994 e com negociaçỏes previstas até 2005, compreende um vasto projeto de cooperacão hemisférica liderado pelos Estados Unidos e centrado na conformaçăo de uma área de livre comércio do Alasca à Terra do Fogo. O MERCOSUL negocia em bloco, assim como a CAN e os paises da América Central e do Caribe, o que não é o caso dos paises do NAFTA e do Chile. Este viu recusada, pelo Congresso dos Estados Unidos, em 1996, a autorização ao Executivo para a negociação de um acordo de livre comércio, aproximando-se por isso do MERCOSUL para concretizar o que parecia ser sua adesão plena ao bloco do Cone Sul. Não obstante, no final de 2000 foram anunciadas as negociaçoes com os Estados Unidos, o que gerou desconforto no Brasil e nos demais países do MERCOSUL por ocasião do encontro presidencial desse ano.

$N a$ reunião ministerial da ALCA realizada em maio de 1997 em Belo Horizonte foi consagrado o princípio dos "building blocks", segundo o qual não haveria diluição dos esquemas subregionais na zona de livre comércio projetada, mas ainda assim a amplitude e a profundidade dos compromissos a serem eventualmente alcançados representam um dos maiores desafios à manutençăo co MERCOSUL enquanto entidade independente. Em março de 1998, na reuniāo ministerial de San José, foram definidas a forma, o calendário, a localização e as presidências sucessivas do processo negociador da ALCA, com acordo sobre os princípios de transparência e de decisão consensual e o estabelecimento dos seguintes grupos de negociação: acesso a mercados; agricultura; serviços; investimentos; subvençoes, antidumping e medidas compensatórias; políticas da concorrência; compras governamentais; direitos de propriedade intelectual e soluçäo de controvérsias. A agenda negociadora extravasa, portanto, os entendimentos internos logrados no âmbito do MERCOSUI, que sequer finalizou o processo de convergência das últimas excecóes à TEC.

Em abril de 2001, em Buenos Aires, no plano ministerial, e no Canadá, logo em seguida, no terceiro summit das Américas, estavan sendo discutidas tanto a antecipação das negociaçōes hemisféricas como seu fim hipotético antes de 2005, o que colocava em questão o futuro imediato do 
MERCOSUL. Pelo calendário normal, definido na Costa Rica, o Brasil e os Estados Unidos exerceriam a co-presidência das negociaçöes da ALCA na fase final e decisivo do processo hemisférico.

\section{O MERCOSUL como projeto politico: perspectivas}

O MERCOSUL, a despeito das dificuldades previsiveis e inevitaveis, em vista dos prazos relativamente estreitos para o cumprimento de seus objetivos ambiciosos, avançou razoavelmente bem em seus primeiros dez anos, tanto em termos de liberalizaçăo de comércio e de conformação de uma agenda comum de construção progressiva de um espaço económico integrado no Cone Sul, como no plano mais geral dos entendimentos politicos entre os dirigentes dos Estados membros. Certamente que a proposta de se alcançar um mercado comum em täo somente quatro anos partindo da situacão de baixa intensidade no comércio recíproco (pelo meros para o Brasil, que realizava menos de $4 \%$ de seu comércio exterior total na regiäo em 1991) - era pouco realista, levando-se também em consideraçăo as assimetrias de desenvolvimento econômico (sobretudo na área industrial) entre os membros e o nivel ainda pouco elevado de complementaridade inter-setorial e intrafimas, tal como existentes no momento de partida.

O crescimento do comércio e a intensificação dos vínculos de toda espécie entre os membros plenos e os associados podem, portanto, ser considerados como satisfatórios (o Brasil passou a realizar $15 \%$ do seu comércio na regiäo, por exemplo), em especial porque não houve desvio notável de comércio e os fluxos comerciais, de investimentos e financeiros com parceiros externos continuaram a se expandir no mesmo ritmo. A definição de um modelo aberto e competitivo de integraça - em contraste com os vellos esquemas protecionistas, substitutivos e dirigistas do passado - representa um progresso conceitual e mesmo prático na administraçăo do processo de integraçăo. Mais importante, o MERCOSUL implantou um marco de discipina coletiva na definiçäo e na implementação de políticas publicas e setoriais (com destaque para a importante vertente das políticas 
macroeconômicas) que, se não logrou ainda resultados espetaculares em temos de coondenação e de uniformização dessas políticas, conseguiu pelo menos introduzix uma mentalidade de sério comprometimento com metas comuns de estabilidade económica e de responsabilidade fiscal. Cabe ressalcar ainda o papel do MERCOSUL enquanto alavanca negociadora extema, potencializando o poder individual dos paises membros no plano intemacional e aumentando sua credibilidade em face de processos negociadones pluri e multilaterais.

Sem duvida, muito ainda deve ser feito para converter o MERCOSUL em verdadeiro bloco comercial e político dotado de peso próprio na comunidade internacional. Não há ainda definiça de políticas ou posiçoes comuns numa série importante de problemas e de questöes setoriais, inclusive naquelas que pertencem naturalmente a uma uniăo aduaneira como é de fato o MERCOSUL, antes de se lograr o objetivo último de um mercado comum. Considerando-se entretanto os obstáculos e dificuldades de toda ortem enfrentadas pelos paises membros no momento do lançamento do bloco, em 1991 - sobretudo no que diz respeito ao carater inconcluso dos processos de estabilização economica em quase todos eles , pode-se concluir que os progressos foram sensiveis e satisfatórios. Não houve propriamente recuos ou fracassos, tão somente dificuldades compreensiveis para se realizar a integracão completa em setores de impacto real nas estruturas industriais dos paises - como é automobilístico - ou no tecido social e regional de alguns deles - a exemplo do setor acucareiro no norte da Argentina. Outras dificuldades revelam-se na incorporacão insuficiente da nomativa MERCOSUL à legislaça interna ou à própria prática aduaneira e administrativa dos pases membros, criando-se desse modo barreiras não-tarifarias à plena consecucão do objetivo final do mercado comum.

Subsistem, portanto, lacunas do processo integracionista, nem todas vinculadas a problemas percebidos como tais pela opinião pública ou por setores de interesse específico nesse processo. Observadores externos geralmente identilicados com o ambiente unversitario em sua vertente juricica, assim como representantes de centrais sindicais, costumam alertar para o chamado "deficil democrático" do MERCOSUL e para a lalta de 
instituiçōes "fortes", fenômeno mais alegado do que efetivamente existente. Essas questões de organização interna do MERCOSUL serão naturalmente encaminhadas à medida em que forem sendo intensificados os laços não exclusivamente comerciais que ligam entre si os países e os povos do bloco, na medida em que esse aprofundamento de vínculos tende necessariamente a envolver maior número de pessoas e de instituiçöes nas diversas instâncias do processo de integração. O Foro Consultivo Econômico e Social, que permite o diálogo dos responsáveis governamentais com a sociedade civil, passará a formular propostas dotados de maior embasamento técnico e de Cactibilidade operacional na medida em que a agenda da integração permear os programas de trabalho de maior volume de atores sociais, o que não foi manifestamente o caso nestes primeiros dez anos do MERCOSUL (até porque a sociedade civil organizada prefere pressionar diretamente seus respectivos governos nacionais a uma entidade que năo conta com poder decisório na estrutura institucional do bloco).

Não havia, no período decorrido, condições mínimas para se pensar em algum tipo de supranacionalidade das instituições permanentes, como os observadores externos mais realistas terão admitido. Em outros termos, o MERCOSUL realizado foi o possível, não o ideal ou aquele imaginado por observadores acadêmicos ou comentaristas pouco informados dos meios de comunicação. De resto, o alegado caráter supranacional das instituições do MERCOSUL é mais pensado em termos comparativos - direta ou indiretamente - com o modelo europeu, do que refletido efetivamente nas dimensões próprias do MERCOSUL, o que retira à crítica (ou à proposta) caráter prático e factível. Deve-se reconhecer, por exemplo, que não há, no presente momento e após dez anos de experiência, vontade política nos países membros, nem consenso entre seus dirigentes, para a criação de uma estrutura com características supranacionais que inclua um secretariado, um tribunal e um parlamento, segundo o modelo da União Européia.

Por outro lado, um dos aspectos controvertidos e que ainda deverá gerar muita discussão quando for efetivamente enfocado no futuro, diz respeito ao processo decisório do MERCOSUL. Baseado na regra do consenso, o atual sistema permitiu o avanço das negociações, com as conhecidas dificulclades em setores específicos. No momento em que a 
questão de uma eventual estrutura institucional de tipo supranacional vier a ser examinada não haverá como evitar a questão da ponderação de votos, a exemplo do que aconteceu desde o início com o Tratado de Roma que criou - Mercado Comum Europeu e do que acaba de ocorrer numa das muitas revisōes dos textos "constitucionais" da UE, o tratado de Nice que revisou Maastricht. A matéria é delicada porque envolve a questão de soberania e de igualdade de Estados, mas será difícil imaginar a aprovação pelos congressos nacionais dos países maiores, no caso de uma estrutura institucional mais elaborada, de um sistema de votação que não reconheça o peso relativo dos diferentes países membros.

As grandes e difíceis questões com que se defronta o MERCOSUL têm a ver, entretanto, com o seu relacionamento externo, especificamente o desalio da ALCA e seu reforço num contexto de contínuas demandas por maior liberalização e aceitação ampliada dos princípios de tratamento nacional e năo-discriminação no contexto regional e no plano multilateral. Não que a sobrevivência do MERCOSUL esteja ameaçada de modo absoluto, uma vez que o bloco é uma construção política que pode resistir a desafios de tipo comercial ou econômico. Dada sua identidade integracionista e sua vocação de work in progress, o MERCOSUL deve apontar para patamares ainda mais avançados de coordenação de políticas setoriais e macroeconômicas, quando năo de projetos societais, a fim fortalecer-se e implementar "confidence building measures" entre os estratos dirigentes e responsáveis pela condução política e diplomática do processo. O MERCOSUL, assim como acontece no exemplo dos fenômenos monetários, representa basicamente uma questão de confiança dos "usuários": confiança em sua capacidade de "manter valor", de permitir atingir determinados objetivos valorizados socialmente (emprego, renda etc.), que possam ser intercambiados segundo as preferências do "consumidor", e a segurança de que sua presença permeia o conjunto das relações humanas e econômicas cada vez que a necessidade se faz sentir. Embora alguns dos testes a essas capacidades ainda estejam por vir, o MERCOSUL conseguiu realizar, em seus primeiros dez anos, uma demonstraçăo de solidez e reforço progressivo. 


\section{BIBLIOGRAFIA}

Recursos para pesquisa na Internet:

ALADI: www.aladi.org

ALCA: www ftata-alca org

Americas Net/Florida Intemational University: http//americas fiu edu

Asia-Pacific Economic Cooperation/APEC: wwwapecsecorg sg

Association of Caribbean States; www,acs-aecorg

Association of Southeast Asian Nation: wwwasean or id

CAN: wrw comunidadandina org

Cariblan Communty: wwe caricomorg

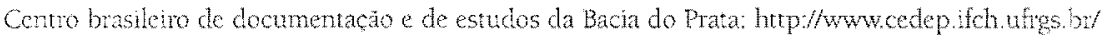

MERCOSUI. (Secretaria Administrativa): www mercosurorg.ty

Ministerio das Relacoes Exteriores do Brasil: http//www mre.govbr

NAPTA: wwwnaftanet

Red Academica uruguaya: wwwtatuedu.uy/mercosu/

UP: wwweuropacuint

Bibliografia secumdarit:

ALMEDA, Patlo Roberto de, A dimensão social dos processos de integraçăo, in CHALOULT, hes et ALMEDDA, Paulo Roberto de (orgs.). Mercosul, Nafta e Alca: a dimensăo social, Săo Paulo, LTr, 1999.

-_- Mercosul: fundamentos e perspectivas. Săo Paulo, LTr, 1998.

"Brasil y el futuro del Mercosur: dilemas y opciones", Integración E Comércio, Buenos Aires, BID-INTAL, 11, 6, sel-dec. 1998, pp. 65-81.

O Mercosul no contexto regional $e$ internacional. São Paulo, Aduaneiras, 1903

BAPTIST, Luiz Olwo. OMcrosul: suas instatucóes e ordenamento jurtico. Sao Paulo, LT, 1998.

MERCADANTE, Amminta de Azevedo; CASELLA, Panlo Borba. Mercosul: dos negociacoes a implantaço. Sâ Paulo, LTr, 1994.

BARBOSA, Rubens Antonio. América Latina em Perspectiva: A Integraçõo Regional da Retótica a Realidade. Să Patolo, Edicoes Aduaneiras, 1991

BASSO, Maristela (org.). Mercosul: seus efeitos juridicos, econónicos e politicos nos Estados-Membros. Porto Alegre, Livarta do Advogado Editora, 1996.

BRANDÃO, Antônio Salazar P. e Lia Valis Pereira (orgs.). Mercosul: perspectivas da integraçấo. Rio de Janeiro, Editoma da Fundaçno Getúlio Vargas, 1996.

CASELIA, Panlo Borba, (coord). Merosul: integraçäo regional e globalizaçāo. Rio de Janeiro: Renovar, 2000

Mercosul: exigências e perspectivas, integraçäo e consolidação do espaço tconomico (1995200]. 2005), Sã Paulo, LT, 1996

CHALLOUE, Yves; ALMEDDA, Paulo Roberto de (orgs). Mercosul, Nafta e Alca: a dimensão social. São Paulo, lit 1999.

COSTA LIMA, Mareos; ALMEIDA MEDEIROS, Marcelo de, O Mercosul no timiar do século XXI, Sảo Paulo, Cortez Editora; Buenos Aires, CLACSO, 2000 
DABENE, Olvier, "Todavia tiene th proyecto el Mercosur?" in COSTA LIMA, Marcos; ALMEDA MEDEIROS, Marcéo de, O Mercosul no limiar do século XXI. Săo Paulo, Cortez Editora; Buenos Aires, CLACSO, 2000, pp. 151-162.

FARIA, Jose Angelo Estrella. O Mercosul: principios, finalidade e alcance do Tratado de Assunçäo. Brasilia, Mimistêrio das Relaçoes Exteriores, 1993.

FLORENCIO, Sergio Abreu e Lima ARAUJO, Emesto Fenrique Fraga Mercosul Hoje. Sho Palo, Editora Alfa-Omega, 1996 .

MELO, Celso Albuquerque de Direito Internacional de Integraçäo. Rio de Janeiro: Renovar, 1996.

PABST, Haroldo. Mercosul: direito da integraçäo. Rio de Janetro, Forense, 1997.

PEEEIRA, Ana Cristina Paulo. Mercosul: o novo quadro juridico das relaçóes comerciais na América Latina. Rio de Janciro: Elitona Lumen Juris, 1997.

PUCCl, Adnana Noemi. Arbitragem Comercial nos paises do Mercosul: analise comparativa da legislaçăo, jurispradencia e doutrina dos autores da Argentina, Brasil, Paraguai e Unuguai relativas à abitragem. São Paulo, LTr, 1997.

THORSTENSEN, Vera. "Relaçes conerciais entre a Unia Europela e o Mercosul impacto da formaça do bloco europen e da politica de comercio externo da UE para o Mercosul", Boletim de Integraça LatinoAmericana, Brasilia, Ministério das Relaçes Extenores, $n^{\circ}$ 14, jult.sept 1994, pp. $33-59$

VELLOSO, Joăo Paulo dos Reis (cood). Mercosul e Nafta: o Brasil e a integraçäo hemisférica. Rio de Janeiro, José Olympio Editora, 1995.

VENTURA, Deisy de Freitas Lima (org). Direito Comunitário do Mercosul. Porto Alegre: Livraria do Advogado Editora, 1997.

A ordem juridica do Mercosul. Porto Alegre: Livrania do Advogado Editora, 1996.

(org.). Mercosul: acordos e protocolos na area juridica. Brasilia, Ministério da Justiça, 1996.

VIGEVANI, Tullo. Mercosul: Impacios para Trabahadores e Sindicatos. Sao Paulo, LTr, 1998.

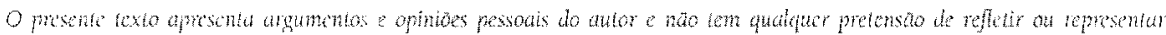

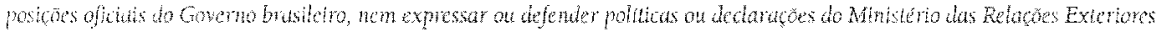

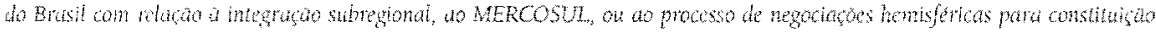

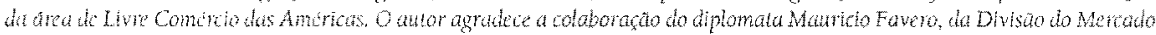

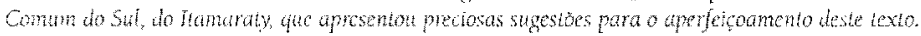

